\title{
IMPACT OF MEDICAL TOURISM: A SYSTEMATIC REVIEW
}

\author{
Vika Wahyudi Anggiri'1), Yaslis Ilyas²) \\ ${ }^{1)}$ Hospital Administration Program, Faculty of Public of Health, Universitas Indonesia \\ 2)Department of Health Administration Policy, Faculty of Public Health, \\ Universitas Indonesia
}

\begin{abstract}
Background: In this era of globalized medicine, online health information is readily accessible to international travel. Medical tourism has captured the interest of the media. Articles, guidebooks, and broadcasts on medical tourism are being published and produced with increasing frequency. Individual motivations for engaging in medical tourism vary widely and may include imperatives such as avoiding waiting time, improving quality, and accessing treatment not available in the home jurisdiction. This study aimed to review systematically the impact of medical tourism.

Subjects and Method: A systematic review was conducted by searching published articles from 2010 to 2019 from databases including ProQuest, Scopus, PubMed, and EBSCOhost. The keyword for this review was "Southeast Asia" AND "medical tourism" OR "health tourism" AND "impact "OR "effect" OR "outcome". The inclusion criteria were English and open acces. After review process 6 articles were included in this review.

Results: An article reported the impact of medical tourism on communication approach. Three articles reported the impact on economic growth. Two articles reported the impact on the health system. Three articles reported the impact on hospital management.

Conclusion: The increase in medical tourism has an impact on several aspects such as communication approach, economic growth, health system, and hospital management.
\end{abstract}

Keywords: medical, tourism, medical tourism

\section{Correspondence:}

Vika Wahyudi Anggiri. Hospital Administration Program, Faculty of Public of Health, Universitas Indonesia, Depok, West Java. Email vika.wahyudi@gmail.com. Mobile 08129520023 . 